OPEN ACCESS

Edited by:

James J. Harynuk,

University of Alberta, Canada

Reviewed by:

Edward Sisco,

National Institute of Standards and Technology, United States

John Vincent Goodpaster,

Indiana University-Purdue University Indianapolis, United States

Maiken Ueland,

University of Technology Sydney,

Australia

*Correspondence:

Paola A. Prada-Tiedemann paola.tiedemann@ttu.edu

Specialty section:

This article was submitted to

Forensic Chemistry,

a section of the journal

Frontiers in Analytical Science

Received: 28 September 2021

Accepted: 10 December 2021

Published: 03 January 2022

Citation:

Nettles $K$, Ford $C$ and

Prada-Tiedemann PA (2022)

Development of Profiling Methods for

Contraband Firearm Volatile

Odor Signatures.

Front. Anal. Sci. 1:785271.

doi: 10.3389/frans.2021.785271

\section{Development of Profiling Methods for Contraband Firearm Volatile Odor Signatures}

\author{
Kirsten Nettles ${ }^{1}$, Cameron Ford ${ }^{2}$ and Paola A. Prada-Tiedemann ${ }^{1 *}$ \\ ${ }^{1}$ Forensic Analytical Chemistry and Odor Profiling Laboratory, Department of Environmental Toxicology, Texas Tech University, \\ Lubbock, TX, United States, ${ }^{2}$ Ford K9 LLC, Las Vegas, NV, United States
}

The early detection and location of firearm threats is critical to the success of any law enforcement operation to prevent a mass shooting event or illegal transport of weapons. Prevention tactics such as firearm detection canines have been at the front line of security tools to combat this national security threat. Firearm detection canines go through rigorous training regimens to achieve reliability in the detection of firearms as their target odor source. Currently, there is no scientific foundation as to the chemical odor signature emitted from the actual firearm device that could aid in increased and more efficient canine training and performance protocols or a better understanding of the chemistry of firearmrelated odorants for better source identification. This study provides a novel method application of solid phase microextraction-gas chromatography-mass spectrometry (SPME-GC-MS) as a rapid system for the evaluation of odor profiles from firearm devices (loaded and unloaded). Samples included magazines $(n=30)$ and firearms $(n=15)$ acquired from the local law enforcement shooting range. Headspace analysis depicted five frequently occurring compounds across sample matrices including aldehydes such as nonanal, decanal, octanal and hydrocarbons tetradecane and tridecane. Statistical analysis via principal component analysis (PCA) highlighted a preliminary clustering differentiating unloaded firearms from both loaded/unloaded magazines and loaded firearm devices. These results highlight potential odor signature differences associated with different firearm components. The understanding of key odorants above a firearm will have an impact on national security efforts, thereby enhancing training regimens to better prepare canine teams for current threats in our communities.

Keywords: firearms, contraband, canine detection, volatile organic compounds, SPME-GC/MS, odor signature

\section{INTRODUCTION}

Globally, firearms are recurrently the lethal means in forensic casework ranging from homicide to suicide, and accidental injuries, indicating an importance in law enforcement and national security. Firearm-related death rates vary between locations, and the contributory elements in these global discrepancies are related to multifaceted issues that differ by region and country which can include illegal drug trades, mental health, substance abuse, socioeconomic status, etc. (Naghavi et al., 2018). According to the 2019 FBI crime statistics reporting, firearms, no matter the type, were used in most homicides with approximately 10,258 cases (FBI, 2019). Out of the total firearms used in the reported 
10,258 homicides, handguns were the most common type at 6,368 homicides (FBI 2019). Speaking specifically about violent crimes, firearms were used in $73.7 \%$ of the nation's murders, $36.4 \%$ of robberies, and $27.6 \%$ of aggravated assaults (FBI, 2019). Therefore, the early detection of firearm threats is critical to the success of any law enforcement operation to prevent a shooter from inflicting harm to innocent victims. Possessing firearms are important for protection purposes, but there is a problem when firearms become contraband, meaning they should not be held in a certain area or when the criminals conceal or bury the weapon used in the commission of a crime. Since 2013, there have been 569 incidents of gunfire in schools, including 210 deaths and 416 injuries (EverytownResearch, 2019). From 2017-2019, there was an increase from 69 incidents to 130 incidents of gunfire on school grounds (EverytownResearch, 2019). With an increased number of mass shootings in our country, prevention tactics such as firearm detection canines are at the front line of security tools available to law enforcement personnel.

As with any other detection discipline, firearm detection canines go through rigorous training regimens to achieve proficiency and reliability in detecting firearms as their target odor source. Canine association guidelines for certification require training on basic odors which include whole firearms with varying periods of time since last discharge (new and used; cleaned and recently fired), loaded/unloaded magazines, disassembled firearm parts (barrel, upper receiver), fired casings or cartridges and gun powders (SWGDOG, 2020). This assortment of matrices constitutes the target odors that are commonly implemented for routine training and testing purposes for firearm detection. These target odor sources are hidden in various types of search scenarios that includes buildings, vehicles, open areas (i.e., open fields, wooded areas), baggage/packages, and person searches (SWGDOG, 2020). However, for optimal use and field applications, these biological systems need to be trained with high quality training regimens that are on par with current operational needs. Currently, there is no scientific foundation as to the chemical odor signature emitted from the actual firearm device. It could aid in increased and more efficient canine training and performance protocols and a better understanding in terms of the odor chemistry originating from firearm devices.

With respect to firearm related research relevant to detection capabilities, gunshot residue analysis (GSR) is a focal point within the forensic practice. GSR has been used in investigations to provide crucial information as to possible association of the weapon with a possible suspect, time since discharge, and shooting distances. Scientific reviews have been previously published describing residue composition and distribution detection technologies, and evidentiary interpretation value (Dalby et al., 2010; Chang et al., 2013; Maitre et al., 2017; Blakey et al., 2018; Shrivastava et al., 2021). The residues consist of various compounds that are released during the discharge of the cartridge in a firearm. It is then an explosion that creates a sequence of events yielding various VOCs and primer mixtures, resulting in discharge of oxidation products and pyrolytic byproducts (Gallidabino et al., 2017). Organic GSR particles originate from propellants created from additives, stabilizers, plasticizers, or flash inhibitors (Dalby et al., 2010). There are many aromatics and nitrogen containing compounds found in the residue (Andrasko and Ståhling, 2000; Andrasko and Ståhling 2003; Joshi et al., 2009; Weyermann et al., 2009; Dalby and Birkett, 2010; Dalby et al., 2010; Reid et al., 2010; Gallidabino et al., 2014; Gallidabino et al., 2015; Tarifa and Almirall 2015; Gallidabino et al., 2017; Feeney et al., 2020). These studies have analyzed volatile constituents using adsorbent mediums for the collection of samples from the targeted surface or testing the headspace above smokeless powder samples. With respect to headspace odor analysis, one study utilized SPME to identify naphthalene and thermal energy analysis (TEA2) to help in understanding the time since discharge (Andrasko and Ståhling, 2000; Andrasko and Ståhling, 2003). The SPME fiber was inserted into the muzzle of the rifle and pistol barrels to test the headspace of the firearms at different time intervals after discharge. Andrasko's study was important because it was one of the first studies to use the firearm itself as a sampling source. Although, studies have evaluated smokeless powder and GSR volatile components, to date, none have embarked on an evaluation of VOCs emanating from firearm surfaces as the target odor source. The study is novel, because time since discharge or other shooting occurrences are not being evaluated, but rather, the goal is to obtain a snapshot of target volatiles being emitted from key parts such as a magazine or the whole handgun device that not only come from shooting incidents, but rather from the firearm itself before it has even been used.

This study will strain to fill the gap by testing both unloaded/ loaded magazines and firearms as the actual sampling source. Using the analytical methodology of SPME-GC-MS to extract the headspace of each sample, will allow for an understanding of the volatile odor signatures present in this type of forensic specimen. The knowledge of volatile odor signatures in firearms is important for contraband canine detection as well as for enhancing ballistic investigative purposes.

\section{MATERIALS AND METHODS}

To identify the VOCs emitted from collected samples, analysis was completed via SPME-GC-MS. The headspace of the firearms was sampled with a commercially available $50 / 30 \mu \mathrm{m}$ divinylbenzene/carboxen/polydimethylsiloxane (DVB/CAR/ PDMS) fiber (Supelco, Sigma Aldrich) (seen in Figure 1). As this was an exploratory proof of concept study, the fiber chosen was made in relation to a general extraction capacity for volatile and semi-volatile components within a molecular weight range of MW 40-275. Each SPME fiber was conditioned for $30 \mathrm{~min}$ at $250^{\circ} \mathrm{C}$ at least three times to guarantee each fiber was clean and ready for use prior to matrix sampling.

The jars were rinsed with methanol and placed in the oven at $105^{\circ} \mathrm{C}$ for an hour. The lids and septas were also rinsed in the same manner and placed in the oven for 15 min. Blanks of the jars were taken at the beginning of each sampling week. Blank headspace samples were analyzed for each jar used and taken 


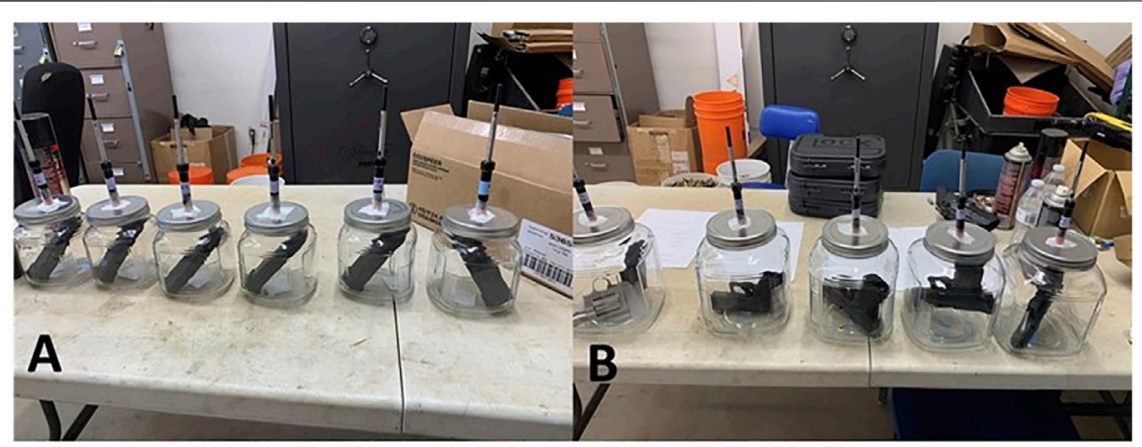

FIGURE 1 | Headspace sample extraction set-up (A) magazine sampling (B) full firearm sampling.

before any firearm and/or magazine were placed inside to verify the volatile came from the sample and not the containment system. Corresponding background subtractions were made in cases where the same compound was found in blank jar headspace analysis. Even though the scope of the study was not to study samples of spent casings or ammunition, a preliminary control sampling was performed on brand new ammunition. This control allowed for a quick snapshot of target odor volatiles in this odor source. The ammunition was Federal, 45 automatic, Aluminum Champion, full metal jacket (FMJ), 200 cartridges, 230 Grain, (Anoka, MN). A total of 8 or 15 bullets were placed in a sterile glass jar to obtain a headspace odor profile from the ammunition. The number of bullets was chosen with respect to the amount of ammunition typically found within a magazine. A total number of 30 magazines and 15 firearms were utilized for this study. While the main objective was to characterize the odor signatures from magazines and whole firearm devices, the study also utilized the collected sample properties to take a closer evaluation to other variables that might affect the generated odor profile. These variables included age, caliber, brand, date of last discharge, and date of last cleaning (seen in Table 1).

An Agilent Technologies GC 7890A with an Agilent Technologies 5975C inert XL MSD with triple-axis detector (Agilent Technologies, Santa Clara, California) was used to separate and analyze the compounds extracted using the SPME fibers. No internal standards were utilized, as the scope of the study was qualitative rather than quantitative analysis. A splitless injection mode was used for all samples Helium was used as a carrier gas at a flow rate of $1.0 \mathrm{ml} / \mathrm{min}$. The temperature of the injection port was set to $250^{\circ} \mathrm{C}$.

The beginning oven temperature of $50^{\circ} \mathrm{C}$ was held for $5 \mathrm{~min}$ then the temperature was increased from $50^{\circ} \mathrm{C}$ to $160^{\circ} \mathrm{C}$ at a rate of $7^{\circ} \mathrm{C} / \mathrm{min}$ then held again for $2 \mathrm{~min}$. It was then increased from $160^{\circ} \mathrm{C}$ to $260^{\circ} \mathrm{C}$ at a rate of $20^{\circ} \mathrm{C} / \mathrm{min}$ and held for $1 \mathrm{~min}$. The total run time for analysis was $29 \mathrm{~min}$. Mass spectra were repeatedly scanned from 45 to $550 \mathrm{amu}$. Compounds were identified using the NIST 17 (2017) mass spectral reference library. The criteria for the compounds identified were those with detected peaks greater than or equal to a match quality of $90 \%$ or above. No attempts were made to verify the presumptive identifications using physical standards.
Statistical analysis was performed using JMP Prop 15, SAS Institute Inc. 2020. As the study being presented yielded multivariate data from each sample being collected, principal component analysis (PCA) was utilized. Compounds retained for data analysis were classified based on their frequency of occurrence, meaning the compound needed to occur in at least $75 \%$ within each category (i.e., type of sample magazine or firearm, loaded/unloaded). Peak area responses were unit vector standardized for multivariate analysis. PCA was used to reduce the amount of data using the data's correlation matrix. From the PCA, the differentiation of the firearm sample groups was evaluated using the normal contour ellipsoid function, to 1 standard deviation, on the clustered data. Furthermore, a one-way analysis of variance (ANOVA) was used to determine the comparison between the peak area responses of the five commonly occurring compounds and evaluate if there was significant difference in the detected abundance from each sample category (characteristics from questionnaire) at a $95 \%$ confidence interval $(p \leq 0.05)$. The questionnaire categories included age, date of purchase, caliber, brand, last time it was discharged, and last time it was cleaned. For the values that contained significance, a post-hoc test was utilized to analyze the pattern of difference between the means.

\section{RESULTS}

\subsection{Controls}

For purposes of this study, while the scope was not focused on testing a large sample size of ammunition types, brand new ammunition was analyzed to obtain the headspace odor profile encountered in this specimen to compare with the magazine and firearm odor baseline. As different magazines hold different numbers of bullets, the control experiment was designed to simulate the number of bullets loaded in the magazines used for sampling. A magazine can be either single or double stacked, so a good control was an instrumental evaluation of the ammunition itself. Thus, either 8 or 15 bullets were sampled at a time. The compounds identified were camphene, 2Phenylisopropanol, 4-cyanocyclohexene, (-)- $\beta$-Pinene, nonanal (Table 2). 
TABLE 1 | Sample properties of each magazine and firearm sampled from the Lubbock County Sherriff's Office Shooting Range (LCSO).

\begin{tabular}{|c|c|c|c|c|c|c|}
\hline \multicolumn{7}{|c|}{ Sample properties } \\
\hline Magazine & Age (Date of purchase) & Style & Caliber & Brand & Last Time Fired & Last Time Cleaned \\
\hline M1 & 9 years & Semi-Automatic Pistol & $40 \mathrm{cal}$ & Glock & Less than 1 month ago & 2 months ago \\
\hline M2 & 9 years & Semi-Automatic Pistol & $40 \mathrm{cal}$ & Glock & Less than 1 month ago & 2 months ago \\
\hline M3 & 1 year & Semi-Automatic Pistol & $9 \mathrm{~mm}$ & Glock & Less than 1 month ago & 6 months ago \\
\hline M4 & 1 year & Semi-Automatic Pistol & $9 \mathrm{~mm}$ & Glock & Less than 1 month ago & 6 months ago \\
\hline M5 & 1 year & Semi-Automatic Pistol & $9 \mathrm{~mm}$ & $\mathrm{CZ}$ & Less than 1 month ago & 6 months ago \\
\hline M6 & 1 year & Semi-Automatic Pistol & $9 \mathrm{~mm}$ & $\mathrm{CZ}$ & Less than 1 month ago & 6 months ago \\
\hline M7 & 20 years & 1911 Pistol & $45 \mathrm{cal}$ & Chip McCormick & 6 years ago & 6 years ago \\
\hline M8 & 20 years & 1911 Pistol & $45 \mathrm{cal}$ & Chip McCormick & 6 years ago & 6 years ago \\
\hline M9 & 25 years & 1911 Pistol & $45 \mathrm{cal}$ & Chip McCormick & 6 years ago & 6 years ago \\
\hline M10 & 20 years & 1911 Pistol & $45 \mathrm{cal}$ & Chip McCormick & 6 years ago & 6 years ago \\
\hline M11 & 27 years & 1911 Pistol & $45 \mathrm{cal}$ & Colt & 6 years ago & 6 years ago \\
\hline M12 & 1 Year & Pistol & $9 \mathrm{~mm}$ & $\mathrm{CZ}$ & Less than 1 month ago & Less than 1 month ago \\
\hline M13 & 1 Year & Pistol & $9 \mathrm{~mm}$ & $\mathrm{CZ}$ & Less than 1 month ago & Less than 1 month ago \\
\hline M14 & 1 Year & Pistol & $9 \mathrm{~mm}$ & $\mathrm{CZ}$ & Less than 1 month ago & Less than 1 month ago \\
\hline M15 & 1 Year & Pistol & $9 \mathrm{~mm}$ & $\mathrm{CZ}$ & Less than 1 month ago & Less than 1 month ago \\
\hline M16 & 1 Year & Pistol & $9 \mathrm{~mm}$ & $\mathrm{CZ}$ & Less than 1 month ago & Less than 1 month ago \\
\hline M17 & 9 years & Pistol & $40 \mathrm{cal}$ & Glock & 2 years ago & 2 years ago \\
\hline M18 & 9 years & Pistol & $40 \mathrm{cal}$ & Glock & 2 years ago & 2 years ago \\
\hline M19 & 9 years & Pistol & $40 \mathrm{cal}$ & Glock & 2 years ago & 2 years ago \\
\hline M20 & 9 years & Pistol & $40 \mathrm{cal}$ & Glock & 2 years ago & 2 years ago \\
\hline M21 & 9 years & Pistol & $40 \mathrm{cal}$ & Glock & 2 years ago & 2 years ago \\
\hline M22 & 9 years & Pistol & $40 \mathrm{cal}$ & Glock & 2 years ago & 2 years ago \\
\hline M23 & 15 years & Pistol & $22 \mathrm{cal}$ & Advantage Arms & 6 months ago & 15 years ago \\
\hline M24 & 15 years & Pistol & $22 \mathrm{cal}$ & Advantage Arms & 6 months ago & 15 years ago \\
\hline M25 & 15 years & Pistol & $22 \mathrm{cal}$ & Advantage Arms & 6 months ago & 15 years ago \\
\hline M26 & 15 years & Pistol & $22 \mathrm{cal}$ & Advantage Arms & 6 months ago & 15 years ago \\
\hline M27 & 3 years & Pistol & $9 \mathrm{~mm}$ & Glock & 4 months ago & 4 months ago \\
\hline M28 & 3 years & Pistol & $9 \mathrm{~mm}$ & Glock & 4 months ago & 4 months ago \\
\hline M29 & 3 years & Pistol & $9 \mathrm{~mm}$ & Glock & 4 months ago & 4 months ago \\
\hline M30 & 3 years & Pistol & $9 \mathrm{~mm}$ & Glock & 4 months ago & 4 months ago \\
\hline \multicolumn{7}{|l|}{ Firearm } \\
\hline F1 & 4 years & Pistol & $9 \mathrm{~mm}$ & Glock 43 & 5 months ago & 5 months ago \\
\hline F2 & 10 years & Pistol & $9 \mathrm{~mm}$ & Glock 19 & 5 months ago & 1 year ago \\
\hline F3 & 12 years & Pistol & $38 \mathrm{cal}$ & Kahr & 5 months ago & 5 months ago \\
\hline F4 & 2 years & Pistol & $9 \mathrm{~mm}$ & Glock 48 & 5 months ago & 5 months ago \\
\hline F5 & 2 years & Pistol & $38 \mathrm{cal}$ & Glock 42 & Less than 1 month ago & 5 months ago \\
\hline F6 & Over 40 years & Revolver & $38 \mathrm{cal}$ & STW & 14 years ago & 14 years ago \\
\hline F7 & 16 years & Pistol & $9 \mathrm{~mm}$ & Kahr & 5 years ago & 5 years ago \\
\hline F8 & 4 years & Pistol & $9 \mathrm{~mm}$ & Springfield & 2 years ago & 2 years ago \\
\hline F9 & Over 20 years & Pistol & $38 \mathrm{cal}$ & Colt & Less than 1 month ago & 10 years ago \\
\hline F10 & 4 years & Pistol & $9 \mathrm{~mm}$ & Glock 43 & 4 years ago & 4 years ago \\
\hline F11 & 3 years & Pistol & $9 \mathrm{~mm}$ & Glock 45 & 5 months ago & 5 months ago \\
\hline F12 & 9 years & Pistol & $40 \mathrm{cal}$ & Glock 22 & 5 months ago & 5 months ago \\
\hline F13 & 8 years & Pistol & $9 \mathrm{~mm}$ & Glock 19 & 5 months ago & 5 months ago \\
\hline F14 & 2 years & Pistol & $38 \mathrm{cal}$ & Glock 42 & 5 months ago & 5 months ago \\
\hline F15 & 1 year & Revolver & $38 \mathrm{cal}$ & STW 642 & 1 month ago & 1 month ago \\
\hline
\end{tabular}

\subsection{Overall}

In unloaded magazines, the compounds that occurred with at least $75 \%$ occurrence rate, meaning it was in 23 out of the 30 samples, were nonanal, decanal, and tetradecane. In the loaded magazines, the frequent compounds include nonanal, decanal, tetradecane, octanal, and geranyl acetone. In unloaded firearms, the compounds that occurred in at least $75 \%$ of the sampling occurrences, meaning it was in 12 of 15 samples, were nonanal, decanal, octanal, decane, undecane, and tridecane. In the loaded firearms the frequent compounds include nonanal, decanal, octanal, decane, undecane, tridecane, and 4-cyanocyclohexane (Table 2).
Evaluating the chemical odor profile across all sample groups studied (magazine and full firearm), there was a total of five commonly occurring compounds which included: nonanal, decanal, octanal, tetradecane, and tridecane. An example total ion chromatogram across all sample matrices of a $9 \mathrm{~mm}$ Glock pistol can be seen in Figure 2 depicting the common compounds detected. To further investigate the peak area distribution of these five VOCs with respect to sample matrix type, a graphical representation was constructed to visualize amounts for each sample group (Figure 3).

From the five commonly recurring compounds, only nonanal and decanal were identified in loaded/unloaded 
TABLE 2 | Frequency of occurrence of VOCs identified in control ammunition, magazines, and firearms.

\begin{tabular}{|c|c|c|c|c|c|c|c|c|}
\hline \multicolumn{9}{|c|}{ Frequency of occurrence } \\
\hline $\begin{array}{l}\text { Chemical } \\
\text { class }\end{array}$ & $\begin{array}{l}\text { Retention } \\
\text { time }\end{array}$ & Compounds & $\begin{array}{c}8 \\
\text { bullets } \\
n=4\end{array}$ & $\begin{array}{c}15 \\
\text { bullets } \\
n=4\end{array}$ & $\begin{array}{c}\text { Loaded } \\
\text { magazine } \\
n=30\end{array}$ & $\begin{array}{c}\text { Unloaded } \\
\text { magazine } \\
n=30\end{array}$ & $\begin{array}{c}\text { Loaded } \\
\text { firearm } \\
n=15\end{array}$ & $\begin{array}{c}\text { Unloaded } \\
\text { firearm } \\
n=15\end{array}$ \\
\hline Alcohol & 13.020 & 2-Phenylisopropanol & 4 & 2 & 0 & 0 & 0 & 0 \\
\hline \multirow[t]{3}{*}{ Aldehyde } & 9.359 & Octanal & 0 & 0 & 28 & 0 & 0 & 14 \\
\hline & 11.962 & Nonanal & 2 & 4 & 30 & 24 & 13 & 13 \\
\hline & 14.273 & Decanal & 0 & 0 & 30 & 24 & 12 & 13 \\
\hline \multirow[t]{2}{*}{ Alkene } & 9.274 & Camphene & 3 & 3 & 0 & 0 & 0 & 0 \\
\hline & 9.964 & $(-)-\beta$-Pinene & 3 & 3 & 0 & 0 & 0 & 0 \\
\hline \multirow[t]{4}{*}{ Hydrocarbon } & 9.017 & Decane & 0 & 0 & 0 & 0 & 0 & 12 \\
\hline & 11.652 & Undecane & 0 & 0 & 0 & 0 & 0 & 14 \\
\hline & 16.008 & Tridecane & 0 & 0 & 0 & 0 & 0 & 12 \\
\hline & 17.874 & Tetradecane & 0 & 0 & 24 & 26 & 0 & 0 \\
\hline Ketone & 20.636 & Geranyl acetone & 0 & 0 & 23 & 0 & 0 & 0 \\
\hline Nitrile & 11.218 & 4-Cyanocyclohexene & 4 & 4 & 0 & 0 & 14 & 0 \\
\hline
\end{tabular}
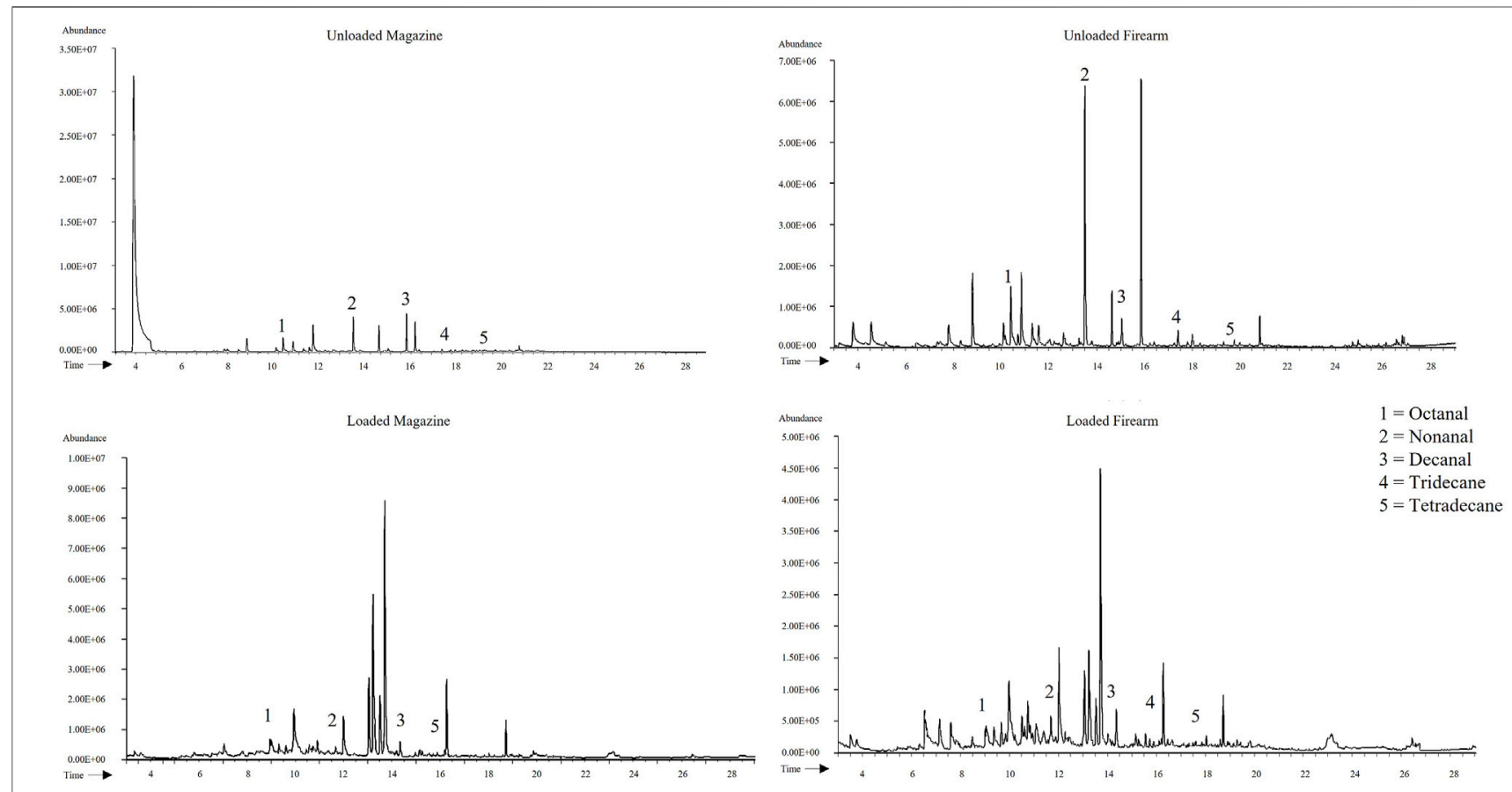

FIGURE 2 | Example Total Ion Chromatograms (TIC) from a 9 mm Glock pistol across all conditions tested (UM: unloaded magazine, LM: loaded magazine, UF: unloaded firearm, LF: loaded firearm).

magazines and firearms. Nonanal had the highest average abundance in every sample matrix, while decanal had the second highest. In general, loaded magazines reported higher average peak areas across the samples tested, followed by unloaded magazines, loaded firearms, and unloaded firearms, respectively. Results highlight that even though accessories such as the magazine are found within the full firearm device, odor signatures differ. Hence, the importance of introducing different firearm part to canines for training regimes to ensure efficacy in operational detection practices. The higher odorant abundance observed in the loaded magazine samples can be attributed to the location of this part within the weapon device. The firearm user must always handle the magazine to load the ammunition, and once placed within weapon remains in a more seclusive environment thus potentially allowing volatiles to linger for longer time periods.

As one of the main objectives of the study was to characterize the odor profile of both magazines and firearm samples, a statistical analysis was made using the detected odor signature profile. PCA was used as the statistical analysis method to see if there was any clustering of samples based on the selected high 

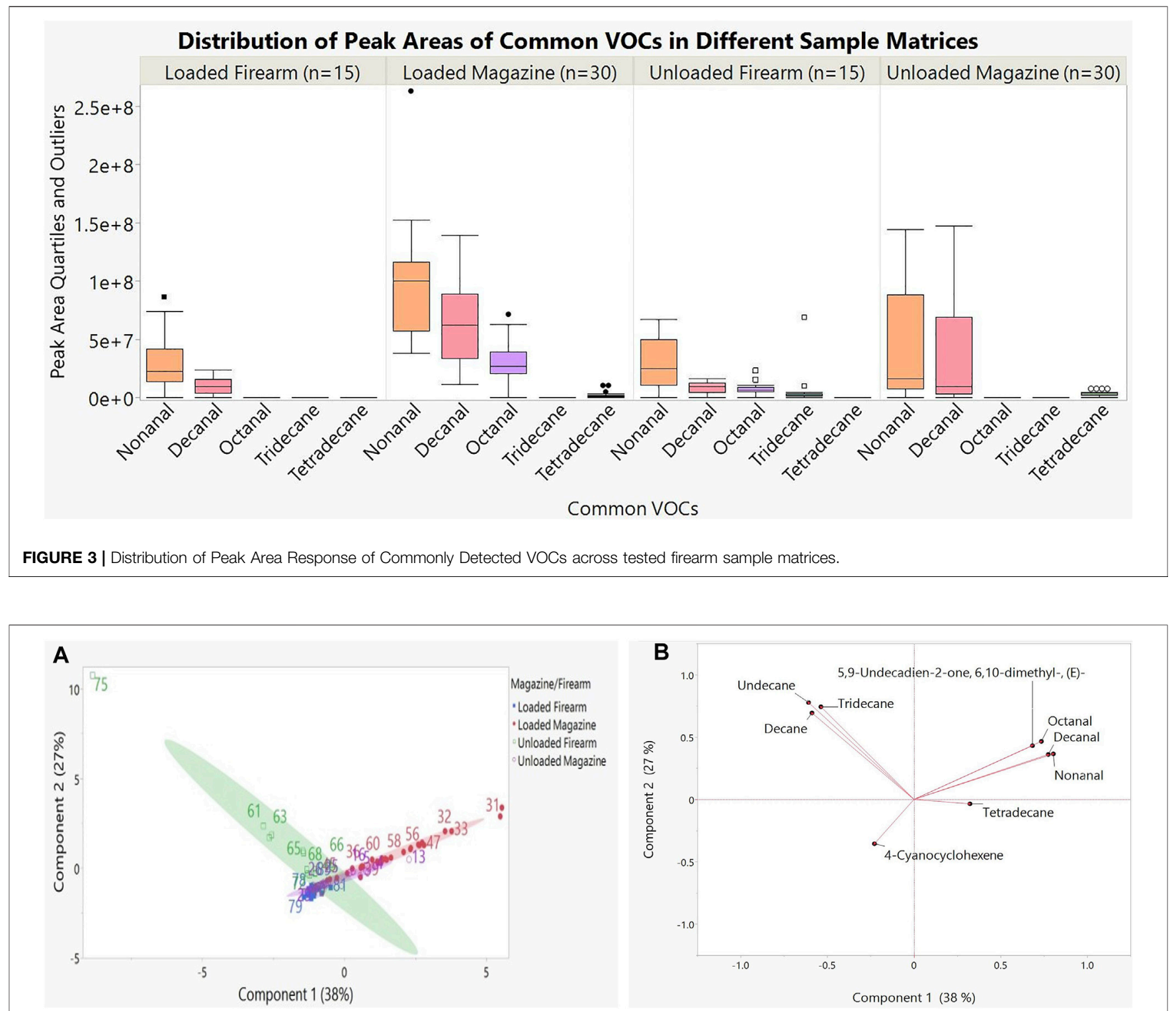

FIGURE 4 | (A). Principal Component Analysis (PCA) 2-D plots of magazine and firearm sampling in the overall comparison (B). PCA Loading Plot of Common Compounds responsible for sample type scores.

frequency compounds described above. The PCA plots were used to monitor the firearm odor profile as a function of sample type (i.e. loaded/unloaded magazine or loaded/unloaded full firearm device). The compounds used for the analysis were the common compounds observed in at least $75 \%$ of the sampling occurrences within each sample type group. As depicted in Figure 4, principal component 1 ( $\mathrm{PC1}$ ) yielded $38 \%$ total variance, while principal component 2 (PC 2) yielded a total of $27 \%$ variation. It can be observed that both unloaded and loaded magazine samples clustered together based on the selected volatile compound array. The loading plot suggest that hydrocarbons such as decane, undecane, and tridecane group separately as opposed to aldehydes and ketones such as nonanal, decanal, octanal and 6,10-dimethyl-5,9-undecadien-2-one which can provide an initial understanding on the odor signatures for these type of sample types. However, in order to generate further suppositions for the correlation of statistical analysis with firearm detection canines, additional studies should confirm chemical characterization with canine field testing to provide the odor profile's behavioral relevance. The unloaded firearms are the only sample group that are not within the same cluster, thereby, providing a preliminary indication of distinctive odor signatures when using the full firearm without ammunition as an odor source. A lower peak area abundance of the high frequency compounds from the unloaded firearm group can explain the clustering observed. Furthermore, this clustering can potentially indicate that common accessories such as the magazine (empty or not) and a fully loaded firearm provide a different chemical odor 
TABLE 3 | Summary of calculated $p$ values across frequently occurring compounds for each corresponding sample property. ( $n=30$ loaded/ unloaded magazines, 15 loaded/unloaded firearms).

\begin{tabular}{|c|c|c|}
\hline Compound & Property & $p$-value \\
\hline \multicolumn{3}{|l|}{ Nonanal } \\
\hline & Age & 0.5241 \\
\hline & Brand & 0.3538 \\
\hline & Caliber & 0.1680 \\
\hline & Last Discharge & 0.9562 \\
\hline & Last Cleaned & 0.9168 \\
\hline \multicolumn{3}{|l|}{ Decanal } \\
\hline & Age & 0.5553 \\
\hline & Brand & 0.2283 \\
\hline & Caliber & 0.1130 \\
\hline & Last Discharge & 0.5178 \\
\hline & Last Cleaned & 0.5069 \\
\hline \multicolumn{3}{|l|}{ Octanal } \\
\hline & Age & 0.1376 \\
\hline & Brand & 0.0236 \\
\hline & Caliber & 0.1044 \\
\hline & Last Discharge & 0.2199 \\
\hline & Last Cleaned & 0.1024 \\
\hline \multicolumn{3}{|l|}{ Tridecane } \\
\hline & Age & 0.0983 \\
\hline & Brand & 0.0666 \\
\hline & Caliber & 0.1706 \\
\hline & Last Discharge & 0.1384 \\
\hline & Last Cleaned & $<0.0001$ \\
\hline \multicolumn{3}{|l|}{ Tetradecane } \\
\hline & Age & 0.2816 \\
\hline & Brand & $<0.0001$ \\
\hline & Caliber & 0.2525 \\
\hline & Last Discharge & 0.0754 \\
\hline & Last Cleaned & 0.0464 \\
\hline
\end{tabular}

Bold values indicate statistically significant value.

profile that can be the result of compound abundances related to ammunition and/or increased device handling.

It is important to note that only nonanal has been reported in other firearm related research and was identified as a compound associated with stabilizers (Feeney et al., 2020). However, nonanal, decanal, and tetradecane have been previously reported as human scent compounds (Prada et al., 2010) which can highlight that their presence might be due to contamination from user handling and not necessarily from the firearm sample itself. It is important to note that the personal history of firearm usage across individuals and related physical activities (normal hygiene, environmental conditions, exposure to external contaminants) can greatly vary, thus adding to the composition of the detected odor profile across both firearms and magazine samples (Chang et al., 2013).

\subsection{Different Sample Properties}

Utilizing one-way ANOVA analysis, firearm sample properties were evaluated as a function of compound abundance. Table 3 provides a summary of the calculated $p$ values across frequently occurring compounds for each corresponding sample property.

\subsubsection{Age (Date of Purchase)}

The age of a firearm is important in both canine detection and ballistic investigations as the weapon utilized can range from being completely new to years in age at the time of use or concealment. The firearm samples utilized in this study ranged in age from 1-16 + years old. None of the common VOCs analyzed had a significant $p$ value for the relationship between age and common compound peak area abundance.

The most common compounds identified were nonanal, decanal, tetradecane, octanal, and tridecane. Older magazines and firearms depicted a decrease in identified peak area abundance. Nonanal reported a higher abundance when compared to the other four commonly occurring compounds. Samples that had an age between 1-8 years reported all five compounds, while ages $13-16+$ did not report all five common compounds within their odor profile.

\subsubsection{Caliber}

Caliber is important because there are many sizes of cartridges used in firearms which are built differently and can therefore cause distinctive characteristics of their manufacture in the generated odor profile. The calibers tested in the study were $9 \mathrm{~mm}, 22 \mathrm{cal}, 38 \mathrm{cal}, 40 \mathrm{cal}$, and $45 \mathrm{cal}$. As with the age sample property, caliber did not depict a statistical significance with respect to any of the five common compound peak area abundances. None of the five compounds has a significant $p$ value with respect to this sample characteristic.

Loaded magazine samples had the highest abundance when discussing different types of calibers. It was followed by unloaded magazines, loaded firearms, and unloaded firearms. The $9 \mathrm{~mm}$ calibers were the only type that showed the five common compounds in every type of sample, while the 38,40 , and 45 caliber highlighted lower reported peak area abundances. The $9 \mathrm{~mm}$ showed the highest abundance and was identified in every sample type.

\subsubsection{Brand}

The brand of the firearm is important because different manufacturers can build the same kind of firearm using completely different materials and methods. The brands utilized in the experiment were Advantage Arms, Chip McCormick, CZ, Glock, Kahr, STW. The one-way ANOVA analysis with respect to brand depicted a significant difference in two compounds, octanal $p=0.0236$ and tetradecane with a $p<0.0001$. A post-hoc test (Tukey-Kramer HSD) was run to understand more specifically which brands had significance. The significant difference in the abundance of tetradecane was between Glock and all the other brands. Comparing the five commonly recurring compounds with respect to brand depicts higher peak area abundances in loaded samples versus unloaded sample matrices. Furthermore, the Glock brand highlighted the five common compounds across all sample matrices evaluated, thereby showing a more reproducible odor signature when compared to the other brands evaluated. 


\subsubsection{Last Time Fired}

Much of the research in firearm detection has been performed in the residues identified from the firearm after discharge. It is important to understand that key odorants from these residues can be important in terms of canine firearm detection. The time since last discharge for samples in this study ranged from 0 months to over a year. None of the commonly occurring compounds reported a statistical significance with respect to time since last discharge. As expected, the least amount of time since discharging the firearm showed the highest abundance of frequent compounds within the set (0-2 months). The samples which are over a year since discharge reported smaller compound abundances compared to the less time since discharge. If a firearm is recently discharged, it can be hypothetically assumed the residue is fresh and therefore highly detectable.

\subsubsection{Last Time Cleaned}

Cleaning routines with firearms vary across individuals, especially when they are being illegally transported or carried. However, the cleaning of a firearm can introduce some distinctiveness within the device, as there are different solvents or lubricants that can be utilized for this purpose. Not cleaning the firearm can also introduce individualistic characteristics, as there is transfer of sweat, dirt, dust to the weapon. Any of these attributes can give key odorants that can change or alter the weapon's odor profile. For this study, the last time since a firearm was cleaned ranged from 0 months to over a year. The one-way ANOVA analysis with respect to weapon cleaning time ranges depicted statistical significance with tridecane at $p<0.0001$ and tetradecane with $p=$ 0.0464. A post-hoc test (Tukey-Kramer HSD) was run to understand more specifically which time periods had significance. The significant difference in tetradecane was between 5,6 months and $0-2$ months, which had a $p$-value of 0.0386 . For the tridecane, following a post-hoc test, the 1 year period was statistically different from all the other time periods. These statistical differences were between the over 1 year period and the $0-2$ months $(p<0.0001), 3-4$ months $(p<0.0017)$ and the 5,6 months $(p<0.0001)$. Lower peak area responses are identified shortly after the firearm is cleaned. Post cleaning time periods of 5-6 months depict higher abundance of compounds. Periods longer than 1 year also highlighted loss of compound detection, which is a similar trend as that observed with time since discharge where prolonged time periods yield less residue particles $(21,22)$.

\section{DISCUSSION}

The most abundant peak areas detected with respect to sample specific properties were observed with the 1 year old, $9 \mathrm{~mm}$, Glock, 0-2 months since the last discharge, and 5-6 months since the last time it was cleaned. The discharge time and time since last cleaned did have an inverse relationship. A short discharge time should have more compounds identified, as well as a long time since the firearm was cleaned. Firearm particles and residue are known for not being very persistent, because there tends to be a large decrease of particles after the first hour of discharging a firearm (Joshi et al., 2011). However, it is important to mention that the compounds detected may not represent the total odor picture, as the method was restricted to using only a single type of fiber chemistry, meaning that other fiber chemistries within SPME technique could be researched in the future to exploit additional volatiles present. Firearm detection canines must be capable of differentiating various background and distractor odors from their target firearm odor to effectively produce the positive alert in this detection discipline. PCA allowed the recognition of novel odor volatiles above the surface of a magazine or firearm. Both of these specimens are routinely utilized for canine training purposes. Whether the statistical analysis correlates with canine behavior and whether these identified odor volatiles are active in the canine odor picture is still unknown. The results however open a chemical characterization pathway for this type of forensic specimen of interest for detection and security applications.

Overall, ANOVA results show significant variance in two categories. With respect to brand, octanal and tetradecane both depicted statistical significance in their reported peak area response. In the last time since it was cleaned, tetradecane and tridecane both indicated statistical significance as well. These identified compounds of statistical significance might represent individualistic characteristics with respect to various sections within a firearm. Furthermore, tetradecane also showed statistical significance when considering the last cleaning occurrence as a variable. Another hydrocarbon, tridecane also showed statistical significance. Once again, these two compounds could represent distinctiveness across firearm sections and handling manipulations which could be crucial to consider when developing testing regimens. While these aldehydes and hydrocarbon volatiles are not typically reported within gunshot residue literature, they have been reported as components in human odor samplings (Prada et al., 2010). Thus, this study could highlight that the routine handling of firearms may transfer odor volatiles onto the firearm device which in turn can impart distinctive odor signatures on that substrate. The chemical characterization of these common VOCs can prove crucial into understanding optimal training protocols in operational setting within canine detection work.

It is important to highlight intrinsic limitations of this preliminary study. The reported volatile odor signatures from the tested firearm-related sample matrices were only conducted with a single type of commercial SPME fiber. Thus, a more comprehensive fiber chemistry optimization can be performed to explore various coatings and extraction capabilities. Since the study was conducted with the local law enforcement shooting range, standardization of the sampling design was achieved by using a sterilized mason jar during the extraction process. This limited the size of the handguns tested in the study. In future work, increasing the variety of weapons and ammunition available can prove valuable to obtain a more detailed odor signature evaluation thus adding more knowledge to the available literature. 
While the compounds identified are novel and may be of human origin and not linked to gunshot residue and overall firearm related research, it is important to highlight that the odor of a target material is not made up of a single odorant but rather a mixture of different odorants, or the target's odor profile. For a complex odor signature such as a firearm, it can be a difficult endeavor to clearly delineate which compounds the canine uses for detection, as extraneous odors such as human handling, weapon cleaning and environment can add or alter the target's odor profile. Hence, the common compounds identified might be a good starting point for this area of study, but not be a complete set to define a firearm odor signature. It is important to highlight that the compounds identified in this instrumental analysis of firearms might not be the exact volatiles canines utilize to make their final detection alert in operational settings. To be able to establish which compounds are important for canine detection, and in what amounts, further research needs to encompass canine testing to link the analytical results with behavioral assessments.

\section{CONCLUSION}

From the instrumental evaluation of the headspace of loaded/ unloaded full firearms and magazines, several compounds were identified as frequently occurring across the sample groups and included: nonanal, decanal, octanal, tetradecane and tridecane. These results indicate that magazines and firearms have characteristic odor signatures that can be utilized for enhanced detection training and technology development. The study is the first to report compounds that are not normally associated with firearms or with associated gunshot residue odor volatiles. In routine GSR studies, common compounds attributed to gunshot residues includes diphenylamine (DPA), 2,4-dinitrotoluene, 2naphthol, nitrocellulose, 2-nitrodiphenylamine (2-NDPA), 4nitrodiphenylamine (4-NDPA), and nitroglycerin (Feeney et al., 2020). This study, however, did not find any of these commonly reported compounds above the headspace of the samples evaluated. It is known that compounds such as DPA and the centralites (ethyl and methyl) are added to increase the shelf life of smokeless powder products (Maitre et al., 2018). In this study, the most common VOC identified throughout the experiment was nonanal, which is a compound associated with gunshot residue as a stabilizer or plasticizer, however, not typically monitored in routine GSR analysis (Feeney et al.,

\section{REFERENCES}

Andrasko, J., and Ståhling, S. (2000). Time Since Discharge of Rifles. J. Forensic Sci. 45 (6), 1250-1255. doi:10.1520/jfs14874j

Andrasko, J., and Ståhling, S. (2003). Time Since Discharge of Pistols and Revolvers. J. Forensic Sci. 48 (2), 307-311. doi:10.1520/jfs2002035

Blakey, L. S., Sharples, G. P., Chana, K., and Birkett, J. W. (2018). Fate and Behavior of Gunshot Residue-A Review. J. Forensic Sci. 63, 9-19. doi:10.1111/15564029.13555
2020). In the overall data, the principal component analysis depicted a preliminary clustering using only the five most common detected compounds across all categories that highlighted the unloaded firearms sample matrix as a separate cluster compared to unloaded/loaded magazines and fully loaded firearms. This analysis indicates potential differences in odor signature profiles across different firearm parts and accessories that are routinely implemented in canine firearm training. This study opens the door to the chemical characterization of firearm samples and accessories to better understand target odorants being emitted from this forensic specimen. Future research needs to focus on the addition of higher number of firearms and/or accessories extending to various types of ammunitions and spent casings. The findings could help elucidate which firearm odor volatiles, if any, could serve as potential surrogates for firearms, identify gaps in the existing literature, and ultimately inform the direction of future research.

\section{DATA AVAILABILITY STATEMENT}

The raw data supporting the conclusion of this article will be made available by the authors, without undue reservation.

\section{AUTHOR CONTRIBUTIONS}

$\mathrm{KN}$ collected, performed the instrumental analysis, and contributed to the data analysis and overall writing of the manuscript. CF helped with study conception and design. PP$\mathrm{T}$ is the senior author on this paper and helped with the overall laboratory design and data analysis as well led study conception, design, interpretation of the results and manuscript editing and writing. All authors reviewed the results and approved the final version of the manuscript.

\section{ACKNOWLEDGMENTS}

The authors would like to thank the Lubbock County Sheriff s Office Firing Range, specifically Sgt. Deon Clements for his kind collaboration in providing all magazines and firearm devices utilized in this research. The authors would also like to thank Shawna F. Gallegos for assistance with figure editing and software plotting.

Chang, K. H., Jayaprakash, P. T., Yew, C. H., and Abdullah, A. F. L. (2013). Gunshot Residue Analysis and its Evidential Values: A Review. Aust. J. Forensic Sci. 45, 3-23. doi:10.1080/00450618.2012.691546

Dalby, O., and Birkett, J. W. (2010). The Evaluation of Solid Phase Microextraction Fibre Types for the Analysis of Organic Components in Unburned Propellant Powders. J. Chromatogr. A 1217 (46), 7183-7188. doi:10.1016/j.chroma.2010.09.012

Dalby, O., Butler, D., and Birkett, J. W. (2010). Analysis of Gunshot Residue and Associated Materials-A Review. J. Forensic Sci. 55, 924-943. doi:10.1111/j.15564029.2010.01370.x 
EverytownResearch (2019). The Long, Shameful List of Gunfire on School Grounds in America [Internet]. EverytownResearch.org. Available From: https://everytownresearch.org/gunfire-in-school/\#ns (accessed Feb 22, 2020).

FBI (2019). Crime in the United States [Internet]. FBI 2019. Available from: https:// ucr.fbi.gov/crime-in-the-u.s/2019/crime-in-the-u.s.-2019/tables/expandedhomicide-data-table-8.xls (accessed Jul 8, 2021).

Feeney, W., Vander Pyl, C., Bell, S., and Trejos, T. (2020). Trends in Composition, Collection, Persistence, and Analysis of IGSR and OGSR: A Review. Forensic Chem. 19, 100250. doi:10.1016/j.forc.2020.100250

Gallidabino, M., Romolo, F. S., Bylenga, K., and Weyermann, C. (2014). Development of a Novel Headspace Sorptive Extraction Method to Study the Aging of Volatile Compounds in Spent Handgun Cartridges. Anal. Chem. 86 (9), 4471-4478. doi:10.1021/ac5004568

Gallidabino, M., Romolo, F. S., and Weyermann, C. (2015). Characterization of Volatile Organic Gunshot Residues in Fired Handgun Cartridges by Headspace Sorptive Extraction. Anal. Bioanal. Chem. 407 (23), 7123-7134. doi:10.1007/ s00216-015-8874-0

Gallidabino, M., Romolo, F. S., and Weyermann, C. (2017). Time Since Discharge of $9 \mathrm{Mm}$ Cartridges by Headspace Analysis, Part 2: Ageing Study and Estimation of the Time Since Discharge Using Multivariate Regression. Forensic Sci. Int. 272, 171-183. doi:10.1016/j.forsciint.2016.12.027

Joshi, M., Delgado, Y., Guerra, P., Lai, H., and Almirall, J. R. (2009). Detection of Odor Signatures of Smokeless Powders Using Solid Phase Microextraction Coupled to an Ion Mobility Spectrometer. Forensic Sci. Int. 188 (1-3), 112-118. doi:10.1016/j.forsciint.2009.03.032

Joshi, M., Rigsby, K., and Almirall, J. R. (2011). Analysis of the Headspace Composition of Smokeless Powders Using GC-MS, GC- $\mu$ ECD and Ion Mobility Spectrometry. Forensic Sci. Int. 208, 29-36. doi:10.1016/j.forsciint.2010.10.024

Maitre, M., Kirkbride, K. P., Horder, M., Roux, C., and Beavis, A. (2017). Current Perspectives in the Interpretation of Gunshot Residues in Forensic Science: a Review. forensic Sci. Int. 270, 1-11. doi:10.1016/j.forsciint.2016.09.003

Maitre, M., Horder, M., Kirkbride, K. P., Gassner, A.-L., Weyermann, C., Roux, C., et al. (2018). A Forensic Investigation on the Persistence of Organic Gunshot Residues. Forensic Sci. Int. 292, 1-10. doi:10.1016/j.forsciint.2018.08.036

Naghavi, M., Naghavi, M., Marczak, L. B., Kutz, M., Shackelford, K. A., Arora, M., et al. (2018). Global Mortality from Firearms, 1990-2016. JAMA 320 (8), 792-814. doi:10.1001/jama.2018.10060
Prada, P. A., Curran, A. M., and Furton, K. G. (2010). Comparison of Extraction Methods for the Removal of Volatile Organic Compounds (VOCs) Present in Sorbents Used for Human Scent Evidence Collection. Anal. Methods 2 (5), 470. doi:10.1039/b9ay00239a

Reid, L., Chana, K., Bond, J. W., Almond, M. J., and Black, S. (2010). Stubs Versus Swabs? A Comparison of Gunshot Residue Collection Techniques. J. Forensic Sci. 55 (3), 753-756. doi:10.1111/j.1556-4029.2010.01332.x

Shrivastava, P., Jain, V. K., and Nagpal, S. (2021). Gunshot Residue Detection Technologies-A Review. Egypt. J. Forensic Sci. 11, 11. doi:10.1186/s41935-02100223-9

SWGDOG (2020). Swgdog Sc8- Substance Detector Dogs Firearms Detection [Internet]. Available from: https://swgdog.fiu.edu/appendices/appendix_8-5. pdf (accessed Mar 11, 2020).

Tarifa, A., and Almirall, J. R. (2015). Fast Detection and Characterization of Organic and Inorganic Gunshot Residues on the Hands of Suspects by CMVGC-MS and LIBS. Sci. Justice 55 (3), 168-175. doi:10.1016/j.scijus.2015.02.003

Weyermann, C., Belaud, V., Riva, F., and Romolo, F. S. (2009). Analysis of Organic Volatile Residues in 9 Mm Spent Cartridges. Forensic Sci. Int. 186 (1-3), 29-35. doi:10.1016/j.forsciint.2009.01.005

Conflict of Interest: The authors declare that the research was conducted in the absence of any commercial or financial relationships that could be construed as a potential conflict of interest.

Publisher's Note: All claims expressed in this article are solely those of the authors and do not necessarily represent those of their affiliated organizations, or those of the publisher, the editors and the reviewers. Any product that may be evaluated in this article, or claim that may be made by its manufacturer, is not guaranteed or endorsed by the publisher.

Copyright (C) 2022 Nettles, Ford and Prada-Tiedemann. This is an open-access article distributed under the terms of the Creative Commons Attribution License (CC BY). The use, distribution or reproduction in other forums is permitted, provided the original author(s) and the copyright owner(s) are credited and that the original publication in this journal is cited, in accordance with accepted academic practice. No use, distribution or reproduction is permitted which does not comply with these terms. 